\title{
CHARACTERISTIC OF THE KRIVA BARA \\ DEPOSIT AND EXTRACTION TECHNIQES
}

DOI: http://dx.doi.org/10.18509/GBP.2018.11

UDC: 556.541:553.068.2(497.2)

\author{
Maya Grigorova \\ Ivaylo Koprev \\ University of Mining and Geology “St. Ivan Rilski”, Bulgaria
}

\begin{abstract}
The "Kriva bara" deposit is located on the left terrace of the Iskar River in Sofia valley. The area of Sofia valley is built of Neogene ponds and Quaternary sediments. Fieldsurrounding mountains are made of Paleozoic, Triassic and Jurassic sediments formed in a different facial environment and which have a specific layers arrangement and substantial composition.

The "Kriva Bara" field is made up of the alluvial deposits of the Iskar River, represented by sands, gravel and clay, including thick layer of ballast, small lenses and thin layers of sandy clays. Alluvial deposits lie horizontally.

The application of extraction techniques aims to achieve the complex and safe carrying out the extraction works, observing the environment protection and achieving healthy and safe working conditions.
\end{abstract}

Keywords: Extraction techniques, alluvial deposits, environment conditions.

\section{INTRODUCTION}

In the present study is described extraction technique in "Kriva Bara" deposit according to its specific geological features and terrain conditions. The aim of the research is to locate the position and to investigate the quality of the raw materials (mostly sand and gravel mixed with clay) in the alluvial deposits of the Iskar River. Sand and gravel is one of the main sources of natural aggregate. These materials are commonly used construction materials and are used with a binding medium to form concrete, mortar, and asphalt or alone as in highway base courses, railroad ballast, and other similar applications. Sand and gravel and crushed stone are widely distributed, used throughout the world, and together comprise the number one non-energy mineral resource in the world, both in terms of value and volume [1]. The highest quality materials, used for making concrete, often is found near active river channels. These materials may also be present in old river terraces where river channels once were located.

\section{PHYSICAL-GEOLOGICAL FEATHURE}

The area of interest is situated in the northeastern part of the Sofia valley. Numerous geological studies have been done on sand and gravel along the Iskar River in the eastern part of Sofia. The area of Sofia valley is built mostly of Neogen ponds and quaternary sediments. Field-surrounding mountains are made of Paleozoic, Triassic, Jurassic and Lower-Grain sediments formed in different facial conditions and have a specific layer and substantial composition. 
The Neogen is represented by sandy clay and gravel Pliocene deposits with thickness reaching $800-900 \mathrm{~m}$. At the end parts of the valley they are exposed directly to the surface or in some arias remain covered by quaternary deposits of low thickness.

Quaternary deposits are widely distributed in the Sofia Valley and in general their type is quite different in the valley.

Alluvial deposits are built of sand, gravel and clay and their thickness varies from 5 to 10 $m$ to several tens of meters.

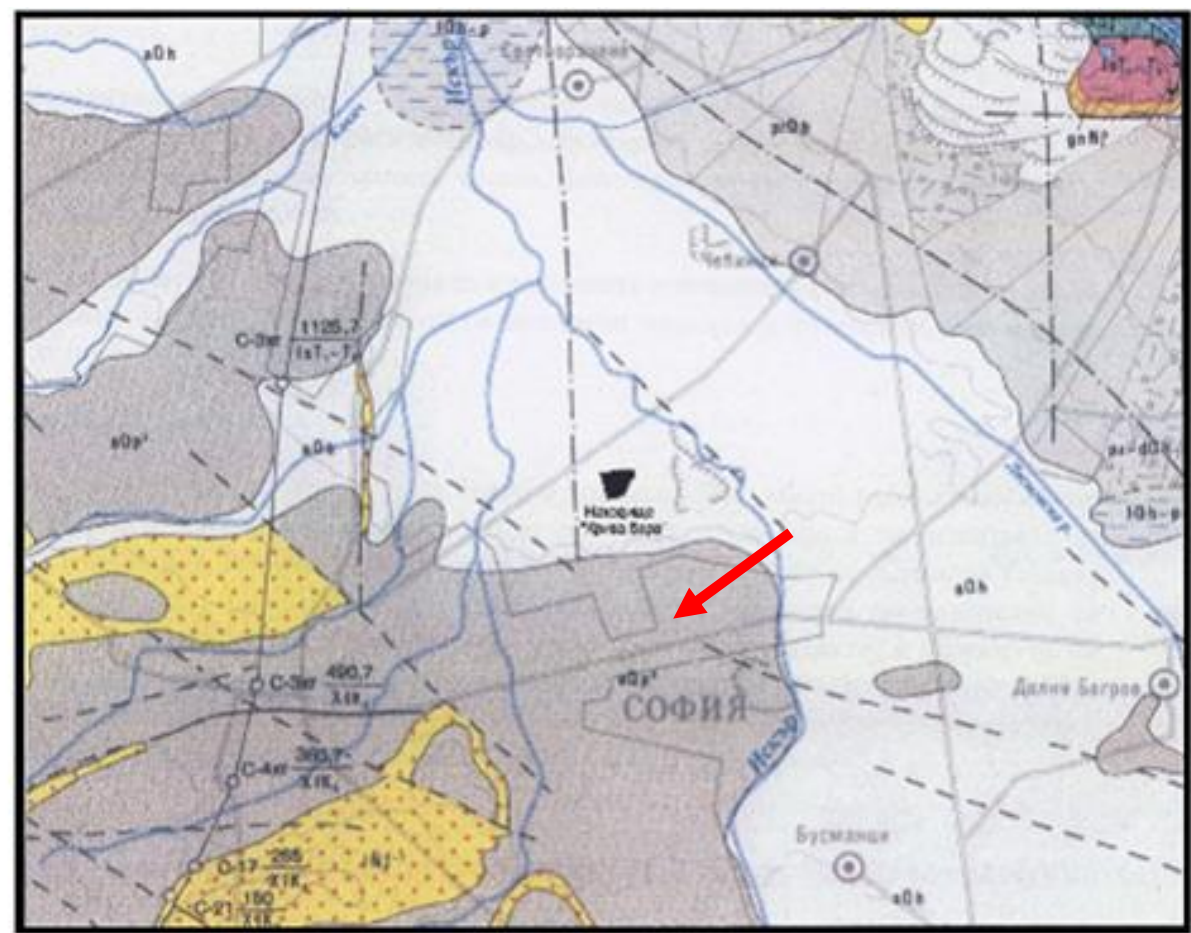

ant gravel sand, clay

Alluvial formations and terrace mostly gravel , clay, sand indirl Permeable alluvial formations mostly sand and gravel

Permeable formations gravel, boulders
Lake-ponds formations sand , clay and peat

Alternating sand, clay, siltstone, gravel

Figure 1. Geological map of the region of the deposit.

The following types of groundwater are found in the region of Sofia valley:

- Groundwater in alluvial deposits of the Iskar River and its tributaries. The gravel and the sand presented in the alluvial deposits here have good filtration properties;

- Pressure waters in the upper Pliocene horizon. These waters are accumulated in the shallow Pliocene sand and are subject to industrial water supply. Pliocene horizon is represented by alternating sand, sandy clay and clay [2].

\section{QUALITATIVE CHARACTERISTIC OF DEPOSIT AND CLASSIFICATION OF RESOURSES}

The "Kriva Bara" deposit is made up of the alluvial deposits of the Iskar River, represented by sand, gravel and clay. The content of sand in ballast ranges from 37,64\% to $65,34 \%$, on average $54,56 \%$. The average sand content is $35,87 \%$. The mineral 
composition is mainly of quartz, feldspar and small rock fragments. The grain-size composition is variable, but no noticeable difference in depth is observed.

The gravel content in the ballast ranges from $24,3 \%$ to $58,6 \%$, averaging $36,64 \%$. Its contents, as well as the grain size, are changing both spatially and in depth.

Because of the relatively simple geological structure of the deposit and different degree of exploration, the method used for calculating resources is those of geological blocks.

This method is most appropriate because of the following:

- Size and shape of the useful material - the ballast creates a sub-horizontal body;

- Relative homogeneous chemical composition in depth;

- Fairly good endurance with regard to the geological structure and the qualitative indicators of the useful material;

- The method allows fast and simply to be determined the quantity of the studied raw material [2].

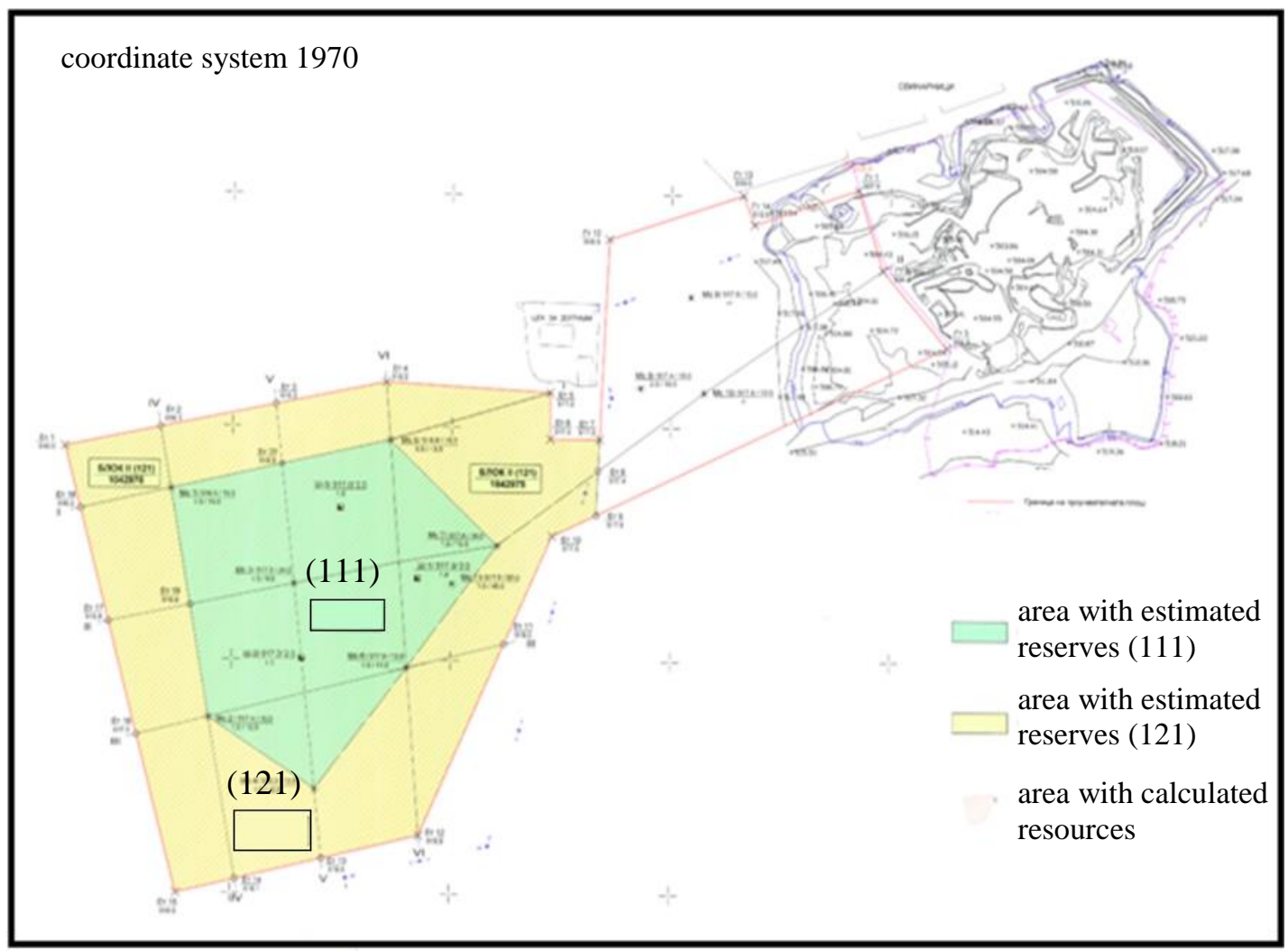

Figure 2. Method of geological blocks for resources estimation in the "Kriva bara" deposit [2] (with changes)

On the figure 2 is shown map of estimated resources in the "Kriva bara" deposit.

Proven stocks (111) are estimated within the boundaries of the contour outlined by the drilling and geophysical work within the boundaries of the area. The field was studied with 8 drillings with a depth of $13,50 \mathrm{~m}$ to $24,0 \mathrm{~m}$. They are located in profile lines, at a distance of 80-100 meters from each other.

In recent years geophysical methods have been commonly used to study alluvial plains, the depositional mechanisms of river sediments, pollutant infiltration and etc. To characterise the lithology and thickness of near water-bed materials is possible to be used electrical resistivity tomography (ERT). This method has potential to detect the near-bed layer with significantly good resolution [3]. 
Probable stocks (121) are estimated by extrapolation of proven reserves limited to the area of study up to $170 \mathrm{~m}$.

\section{DEVELOPMENT AND EXTRACTON PARAMETERS}

Instream gravel mining involves the mechanical removal of gravel and sand directly from the active channel of rivers and streams. Active channel deposits are desirable as construction aggregate because they are typically durable (weak materials having been eliminated in river transport), well-sorted, and frequently located near markets or on transportation routes. Instream gravel mining commonly causes incision of the channel bed, which can propagate upstream and downstream for kilometers [4].

Sand and gravel has been traditionally mined underwater by two basic methods, one of which employs a stationary, or anchored, dredge that digs a pit, and the other of which uses a transient dredge that skims off the top layer of material as the vessel moves along. The choice of method depends on such variables as extent, thickness, and composition of the deposit; sand-to-gravel ratio; type and depth of overburden (unwanted material overlying the deposit: usually muds, silts, or clays) if any; location with respect to shore facilities [5].

The implementation of the selected extraction technique aims to achieve the complex and safe extraction of the mining works, observing the environmental conditions and achieving healthy and safe working conditions.

The extraction works were carried out with a floating excavator type "Greifer" with a bucket volume of $4 \mathrm{~m}^{3}$.

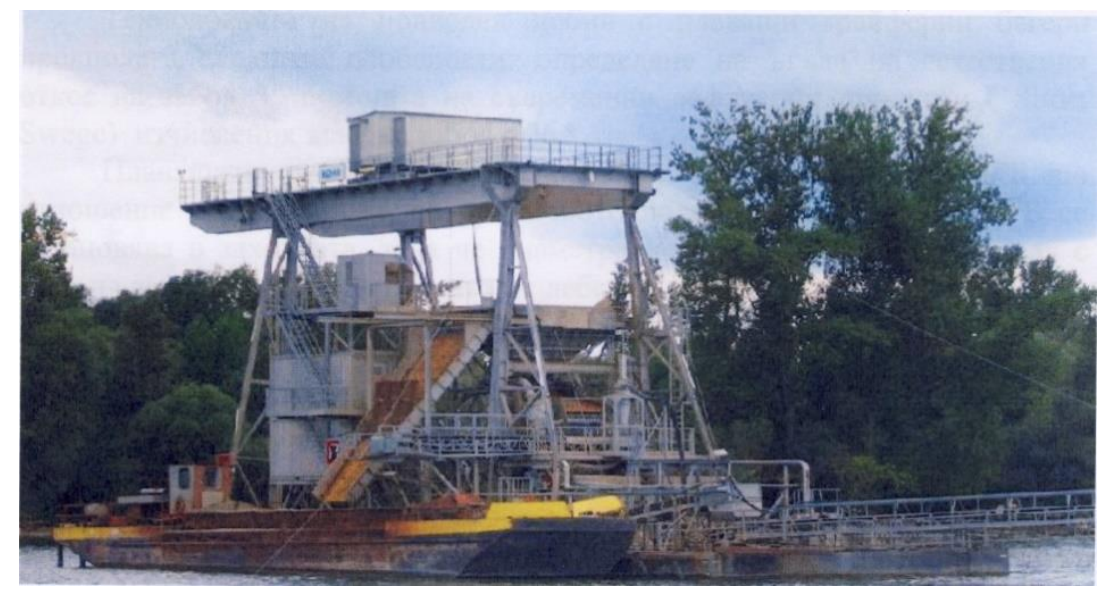

Figure 3. Floating excavator

The scheme of development is a radial flow diagram. This approach allows better management of the quality of the extracted raw material.

This creates an opportunity for selectivity in the work flow which is required due to the presence of areas with clay layers. The extracted clay materials were transported to the shore and subsequently used to fill the space and recultivate the quarry. That is very important step in extraction process because direct extraction of alluvial material from river channels causes far greater impacts than floodplain extraction. The effects of bed sediment mining are more severe: where material is extracted at a rate greatly exceeding the replenishment rate, where extraction is from single-thread rivers, that are generally associated with relatively low rates of catchment sediment supply [6]. 


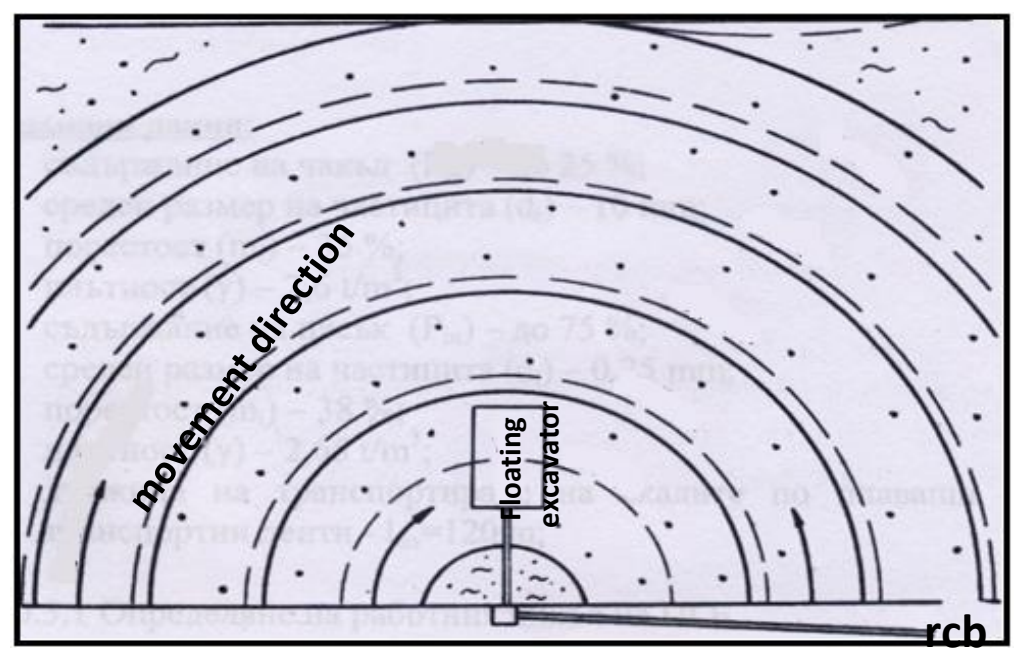

Figure 4. Radial system of development

The extracted by the excavator material is transported to the shore by floating conveyor belts, from where it is fed to the receiving wash-sorter plant.

\section{CONCLUSION}

The mining of sand and gravel from rivers is a common practice because of its importance to the industry. Alluvial rivers have been used as a source of sediment for a variety of industries. Extraction of sand and gravel from rivers is a global practice in countries subject to rapid urban and industrial growth over recent decades. Results outlined here provide useful information about the size, volume and quantity of sand and gravel in "Kriva bara" deposit. It was found that after washing the sand meets the requirements for making all brands of plain concrete. By grain size and physical-mechanical properties gravel conforms to the standard as materials for ordinary concrete. Due to this fact these raw materials become the principal ingredient in an unusually strong and long-lasting construction material - concrete. When combined with asphalt, sand and gravel in "Kriva bara" deposit become the aggregates forming the major element of asphaltic concrete, which is widely used as a paving material.

The need for raw materials is a prerequisite for their demand on the market and hence for geophysical investigations and mining operations. Exploration and mining activities, including sediments mining, are faced with the challenge to ensure both the need for raw materials for the industry and to preserve the fragile ecological balance.

\section{REFERENCES}

[1] Langer, W. H., A General Overview of the Technology of In-Stream Mining of Sand and Gravel Resources, Associated Potential Environmental Impacts, and Methods to Control Potential Impacts, p.2-3, 2003.

[2] Koprev, I., Report on the Geophysical Studies of the Kriva Bara Field, 2007.

[3] Grigorova, M., Koprev, I., Application of electrical resistivity tomography for sands underwater extraction, International Scientific Conference GEOBALCANICA, Macedonia, under print.

[4] Kondolf, M., G., Geomorphic and environmental effects of instream gravel mining, Landscape and Urban Planning, Vol. 28, Issues 2-3, p. 225-243, 1994. 
[5] Cruickshank, M. J and Hess, H. D., Marine sand and gravel mining, 1978.

[6] Rinaldi, M., Wyzga, B. and Surian, N., Sediment mining in alluvial channels: physical effects and management perspectives, River Res. Applic. 21: 805-828, DOI: 10.1002/rra.884, 2005. 